\title{
Frzb knockout reveals the complexity of Wnt signaling in joint homeostasis
}

Publishing in Arthritis Research \& Therapy, Rik Lories and colleagues at the Katholieke Universiteit Leuven, Belgium, provide new insight into the role of the FRZB gene-encoding a Wnt signaling pathway antagonist that has been linked to osteoarthritis (OA) - in joint homeostasis.

Transcriptome analysis of articular cartilage and subchondral bone suggested extracellular matrix, cell adhesion and cell cycle alterations occur in Frzb $b^{-/-}$mice, compared with wild-type control mice. The changes observed might contribute to the increased susceptibility of $\mathrm{Frzb}^{-/-}$ mice to experimentally-induced OA, previously described by Lories et al., and are in keeping with cartilage and chondrocyte phenotypes in OA.

As expected, $\mathrm{Frzb}^{-/-}$mice had increased Wnt pathway gene expression; however, $\beta$-catenin activity was not affected. Of note, many of the upregulated genes are also antagonists of this signaling cascade.
"These data confirm that Wnt signaling in the cartilage-bone unit in the joint is tightly regulated," says Lories, and "may provide an explanation why Frzb $b^{-/-}$mice do not appear to spontaneously develop OA." These findings might also partially explain the inconsistent association of FRZB with OA in humans.

"Compensatory mechanisms in the joint are complex and chondroprotective strategies represent a real challenge," states Lories. Nevertheless, the Wnt pathway represents an attractive target for therapy in OA.

\section{David Killock}

Original article Lodewyckx, L. et al. Tight regulation of wingless-type signaling in the articular cartilagesubchondral bone biomechanical unit: transcriptomics in Frzb-knockout mice. Arthritis Res. Ther. 14, R16 (2012) 